\title{
Sombras e amores: de Eça a Machado
}

\author{
Paulo Motta Oliveira \\ Universidade de São Paulo (São Paulo, Brasil)
}

RESUMO: ESTE ARTIGO PRETENDE REFLETIR SOBRE ALGUNS ASPECTOS DOS PECULIARES REALISMOS DE EÇA DE QUEIRÓS E MACHADO DE ASSIS.

ABSTRACT: THIS PAPER INTENDS TO THINK ABOUT THE PECULIAR REALISM OF EÇA DE QUEIRÓS AND MACHADO DE ASSIS.

PALAVRAS-CHAVE: EÇA DE QUEIRÓS, MACHADO DE ASSIS, REALISMO, ROMANCE. KEYWORDS: EÇA DE QUEIRÓS, MACHADO DE ASSIS, REALISM, NOVEL. 
ntônio José Saraiva, em um livro incontornável sobre a geração de 70, A Tertúlia Ocidental, afirma:

Em 1945, comemorando-se o centenário do nascimento de Queiroz, o autor da presente obra publicou um estudo sobre As ideias de Eça de Queiroz em que se partia do princípio de que Eça de Queiroz era um escritor de ideias, mas só de certas ideias. De fato o lento desenvolvimento da mentalidade portuguesa tornava ainda atual em 1945 a caricatura que Eça fez da nossa sociedade em As Farpas, O crime do Padre Amaro e O primo Basílio, obras que continuavam vivas graças à extraordinária arte do escritor. Todas as outras obras eram consideradas desvios da sua "verdadeira" rota. As idéias de Eça de Queiroz é uma súmula dos clichês então reinantes sobre o escritor. Por isso, uma obraprima como A cidade e as serras era julgada como insignificativa, ou como um regresso a Júlio Dinis (SARAIVA, 1990, p.157).

De fato Saraiva acaba por apontar que talvez seja a uma outra tradição a que se vincula a verdadeira rota do autor:

Nas suas primeiras obras, as Prosas bárbaras (...) Eça é um escritor do gênero que depois se chamou "fantástico", e nas últimas, que são vidas de santos, volta a esse caminho; as suas obras que foram chamadas "realistas" estão entre aquele começo e este fim "fantásticos". São um intervalo numa série vasta, tendo em conta que mesmo na fase "realista" da obra de Eça há vários romances que programaticamente nada têm de realistas, como $\mathrm{O}$ mandarim, As cidades e as serras, A ilustre casa de Ramires, e até onde falta qualquer propósito de coerência e de verossimilhança, como A relíquia. Sem falar de O mistério da estrada de Sintra (SARAIVA, 1990, p. 149).

Poderíamos concluir dos comentários acima feitos, que a verdadeira rota de Eça não seria a do romance realista, pelo qual ficou guardado no imaginário cultural dos países de língua portuguesa. Esse seria um desvio de seu verdadeiro caminho, que estaria nos romances fantásticos ou fantasistas. Estranhas conclusões. Mas elas, certamente, permitiriam que lêssemos com mais acuidade o que poderia parecer apenas uma blague, a divertida e irônica "lettre qui aurait dû être une préface" sobre O mandarim. Lá, como 
o sabemos, o autor afirmará que os portugueses "dans ce coin ensoleillé du monde" são "très idéalistes au fond et très lyriques" e que "toujours nous considerons la fantasie et le éloquence comme deux signes, et les seuls vrais, de l'homme supérieur". Afirmará ainda que os “esprits ainsi formés doivent ressentir nécessairement de l'éloignement pour tout ce qui est realité, analyse, experimentation, certitude objective. Ce qui les attire, c'est la fantasie, sous toutes ses formes" (Queiroz, 1997, p. 835-836.). Há evidentes proximidades entre esse texto e o artigo que Eça publicou em 27 e 28 de julho de 1893, na Gazeta de Notícias, com o título "Positivismo e Idealismo", em que, tentando refletir sobre o retorno das correntes idealistas ou neocristãs na Paris de seu tempo, afirmará:

O homem desde todos os tempos tem tido (...) duas esposas, a razão e a imaginação, que são ambas ciumentas e exigentes, o arrastam cada uma, com lutas por vezes trágicas e por vezes cômicas para o seu leito particular - mas entre as quais ele até agora viveu, ora cedendo a uma ora cedendo a outra, sem as poder dispensar (...).

O positivismo científico, porém, considerou a imaginação como uma concubina comprometedora, de quem urgia separar o homem: - e apenas se apossou dele, expulsou duramente a pobre e gentil imaginação, fechou o homem num laboratório a sós com a sua esposa clara e fria, a razão. O resultado foi que o homem recomeçou a aborrecer-se monumentalmente e a suspirar por aquela outra companheira tão alegre, tão inventiva, tão cheia de graça (...). E um dia não se contém, arromba a porta do laboratório (...) e corre aos braços da imaginação, com quem larga a vaguear de novo pelas maravilhosas regiões do sonho, da lenda, do mito e do símbolo (Queiroz, 2000, p. 1255).

Notemos que, no confronto entre este trecho e a carta que deveria ser prefácio, podemos perceber certas ideias que, em 26 de outubro de 1892, Eça havia ficcionalizado em "Civilização". Parece que a aversão que o autor nota em Portugal às tendências da escola nova faria com que este país estivesse, ao mesmo tempo, atrasado e à frente da Europa culta, pois, por seu arcaísmo, acabaria por já possuir características que o europeu, cansado da fria esposa razão, tentaria reencontrar na abandonada concubina. Podemos aqui escutar a vOz do narrador do conto, que após visitar o Jasmineiro - "supercivilizado 
palácio" em que, naquele momento, "jaziam (...) lamentáveis e grotescas” as "geniais invenções" agora reduzidas a um "montão negro de ferragens, rodas, lâminas, campainhas, parafusos” - afirma:

A chuva de Abril secara: os telhados remotos da cidade negrejavam sobre um poente de carmesim e ouro. E, através das ruas mais frescas, eu ia pensando que este nosso magnífico século XIX se assemelharia um dia aquele Jasmineiro abandonado, e que outros homens, com uma certeza mais pura do que é a Vida e a Felicidade, dariam, como eu com o pé no lixo da supercivilização, e, como eu, ririam alegremente da grande ilusão que findara, inútil e coberta de ferrugem.

Àquela hora, decerto, Jacinto, na varanda, em Torges, sem fonógrafo e sem telefone, reentrado na simplicidade, via, sob a paz lenta da tarde, ao tremeluzir da primeira estrela, a boiada recolher entre o canto dos boiadeiros (Queiroz, 1997a, p. 1524-1525).

Mas não é este o aspecto que mais centralmente aqui nos interessa, e sim outro. O que todos os trechos citados, tanto os de Saraiva como os de Eça, parecem indicar é que seja para a cultura portuguesa, seja particularmente para o autor, as duas vertentes que, no último texto, ele cristaliza na imagem das duas esposas, razão e imaginação, possuem características e fortunas bastante diversas. A primeira teria, entre outras características, a primazia em uma literatura voltada para a descrição e análise do real, enquanto a segunda ligar-se-ia a um outro tipo de escritura, em que o central é o imaginativo e o fantástico. A ficção de Queirós - e não apenas ela, mas também outros textos do escritor - encena um embate entre ambas as esposas em que, tudo o parece indicar, foi a aparentemente abandonada imaginação que acabou por ocupar o primeiro plano.

De fato o confronto começou bem antes, e, se percorre a literatura dos setecentos e oitocentos, aparece de forma mais clara nas várias tendências e embates daquilo que Ian Watt (1990) definiu como a ascensão do romance. Sandra Guardini Vasconcelos, refletindo sobre o romance inglês do século XVIII nota, por um lado, a estreita ligação entre o então novo gênero e a sociedade em que aparece: 
Sem ignorar (...) seus antecedentes, o romance surgiu em cena como uma forma histórica para dar conta de um novo conteúdo social. Poucos gêneros literários parecem ter tido, como o romance, suas raízes mais firmemente fincadas no tempo histórico e em contextos socioculturais específicos. Fruto dos ideais iluministas, (...) o novo gênero não se limitou a refletir os valores de seu tempo, mas ajudou a criá-los. (Vasconcelos, 2002, p. 12.)

Esta íntima relação entre uma forma e o espaço social em que surge darlhe-á certas características que a diferenciam da literatura precedente

Desde o começo, os primeiros romancistas e teóricos do romance, no esforço de desemaranhá-lo do romanesco, acentuaram o compromisso do novo gênero com a verdade, os acontecimentos comuns e naturais, com a probabilidade, opondo-o ao que consideravam um tipo de ficção que transgredia os limites de tempo e lugar, de natureza e possibilidade (Vasconcelos, 2002, p. 27).

Algumas obras de Prevost e Laclos por um lado, e em especial de Defoe, Richardson e Fielding, podem servir de bons exemplos para essa perspectiva. Apesar de ainda estar em busca de uma forma, o romance setecentista tem como uma de suas características, como notou Vasconcelos, a busca de uma maior aproximação ao cotidiano, fugindo dos enredos maravilhosos que caracterizavam a literatura romanesca. Mas essa relação com o verdadeiro e o possível não impedirá que o seu oposto também apareça no novo gênero:

Desde seus primórdios (...) a prosa de ficção oscilou entre a pura fantasia, sem grandes compromissos com as leis da probabilidade e da verossimilhança, e a tentativa de representação fiel da realidade, chegando aos limites do verismo ou naturalismo do século XIX, com todas as possibilidades de combinação, gradação e mescla entre os dois extremos. O romance, dos gêneros narrativos, parece ser aquele que melhor equilibra esses dois pólos (...)

Se os modos não realistas predominaram na prosa de ficção até a ascensão do romance, o novo gênero não sufocou, por completo, o elemento romanesco no interior da narrativa realista. Essa permanência explicaria (...) o (...) retorno [desta tendência não realista] no romance gótico das últimas décadas do século XVIII (Vasconcelos, 2002, p. 28-29). 
Se o gótico surge em fins do XVIII na Inglaterra, os limites e mesmo a definição deste, poderíamos assim chamar, subgênero, são difíceis e imprecisos. Não pretendo aqui discutir as várias posturas sobre ele apresentados, que vão, para apenas citarmos dois exemplos quase opostos, de Devendra P. Varma (1987), que considera que a literatura gótica pode ser circunscrita a um período bastante específico, restando depois disso, dela, apenas algumas manifestações epigonais, como por sinal o título de sua obra bem o indica - The Gothic Flame being a history of the gothic novel in England: its origins, efflorescence, desintegration and residuary influences - a Marie Mulvey-Roberts (1998), no The handbook to gothic literature que organizou, em que apresenta desde a presença do gótico em grande número de autores, até a sua relação com vários outros subgêneros. Numa postura intermediária, Franco Moretti considera que se o que qualifica como gênero gótico pode ser delimitado a um período específico, sendo hegemônico na literatura inglesa entre 1790 e 1815, ele terá um renascimento após 1885 (Cf. Moretti, 2005, p. 23-25 e p. 44).

Parece-me claro que podemos traçar homologias e diálogos entre a eclosão do romance gótico na Inglaterra, ou do roman noir na França, e a íntima relação destes com certos aspectos do Sturm und Drang, em especial com a obra de Schiller, todos eles mostrando a permanência do romanesco no interior do romance, então em construção. As obras de Walter Scott, Eugéne Sue, E. T. A. Hoffman e Mary Shelley só viriam a confirmar a importância de certas transmutações deste veio, ao longo de toda a primeira metade do século XIX.

Sendo bastante redutor, e esquecendo uma série de nuances que seriam necessárias para uma análise mais detida, penso que o título de um livro de Maria Leonor de Carvalho, pode nos servir de pista para pensarmos na presença desse tipo de produções na literatura portuguesa: A literatura negra ou de terror em Portugal nos séculos XVIII e XIX. Existiriam, a partir do título acima, o que também acaba por se confirmar em parte da reflexão que a crítica apresenta em sua obra, duas denominações para esta literatura que, o digamos assim, foge do cotidiano mais realista e banal, na forma como foi aclimatada em Portugal: a "negra", que poderíamos aproximar de certas produções francesas em que o noturno e o incomum são uma marca registrada, e que talvez encontre nos mundialmente imitados Mistérios de Paris, de Eugênio Sue o seu mais importante representante, e, por outro, numa literatura mais próxima do gótico inglês, que poderia ser chamada "de terror", que, se 
tem no Os mistérios de Udolfo, de Anne Redclife uma de suas importantes matrizes, não deixa de estar presente, de forma mais ou menos evidente, em parte da produção de Walter Scott.

Franco Moretti, em trecho a que constantemente retorno, quase no final da análise que faz sobre os mercados editoriais de 1750 a 1850, afirma:

Sim, uma vez que um modelo "satifatório" é encontrado, a história de uma forma se torna realmente diferente. Por volta de 1750, na época da primeira ascensão do romance, ainda não existe tal modelo e o romance é tão diversificado, tão livre - tão louco, de fato - quanto podia ser: Sátira e Lágrimas, Picaresca e Filosofia, Viagem, Pornografia, Autobiografia, Cartas... Mas, cem anos mais tarde, o paradigma anglo-francês está no lugar e o segundo surto é uma história completamente diferente: romances históricos em terceira pessoa, não muito mais. Mais nenhuma invenção morfológica. Difusão: a grande força conservadora. Uma forma: e importada (Moretti, 2003, p. 201).

O mesmo autor, por outro lado, nos gráficos que apresenta sobre a difusão européia seja dos romances britânicos, seja dos franceses, traz outros aspectos interessantes. Mostra que na Espanha - país em vários aspectos próximo a Portugal - dos primeiros, os ingleses, o único autor que possui uma presença importante é Walter Scott. Já sobre os romances franceses aponta que um subgênero - o romance sentimental - e três autores - Eugênio Sue, Alexandre Dumas e Victor Hugo - são os mais traduzidos. Se supusermos, e creio que o podemos fazer pelo menos de forma aproximada, esses dados também válidos para Portugal, poderemos notar que são priorizados na península justamente aqueles autores e correntes que não apresentam, em sua obra, uma preocupação prioritária de representar, de forma realista a realidade que os cerca. No lugar de Sthendal, Balzac e Flaubert, tríade central nesse processo de representação do real na perspectiva de Auerbach (1976), encontramos Sue, Dumas, Hugo e Scott, autores em que, de variadas formas, ocupam um papel relevante características que poderíamos designar como "negras" ou "de terror". O mundo das sombras da Paris desconhecida de Sue, com seus criminosos monstruosos, o universo gótico de certo Hugo e de parte da produção de Scott, os enredos intrincados de Dumas, sejam os históricos s sejam os contemporâneos, como O conde de Monte Cristo, em 
que o mundo do capital e das revoluções é o cenário de amores impossíveis e insaciáveis vinganças: todos estes exemplos são representações que roçam, quando não assumem, o fantástico ou o fantasista.

Moretti aponta com precisão que a história das formas é condicionada pelos espaços em que surgem ou pelos quais viajam, pelas dimensões e maior ou menor permeabilidade desses espaços, em conclusões que se coadunam, por exemplo, com aquelas levantadas por Roberto Schwarz (1981) quando fala da aclimatação das idéias e da forma romance no Brasil. A história das periferias não é atrasada, mais simples ou menos rica: ela é diferente.

Se o romance era, em meados do século XVIII, um gênero em formação, em busca da sua forma, podemos pensar que o romance oitocentista português, cujos primeiros escritores começariam a publicar em torno dos anos 40 e 50, será um gênero que surgirá em contato tenso não com o romance europeu, mas com uma faceta deste, aquela que chega de forma mais preponderante na península, e na qual o "terror" e o "negro" são fundamentais.

Não tenho, aqui, condições de citar muitos exemplos, mas julgo que dos anos 40 e 50, período que seleciono, pois, é o das publicações dos contos e romances de Herculano e dos romances de Garrett, é possível detectar na literatura portuguesa um movimento de incorporação e transmutação de uma série de elementos do que, a grosso modo, poderíamos classificar como gótico. Em Herculano podemos encontrar narrativas claramente fantásticas - de que "A dama pé de cabra" talvez seja o melhor exemplo. Existem outras em que as sombras ocupam um papel central, com personagens que delas surgem para mudar a história, de que certamente o melhor é o bobo do livro homônimo, mas de que o próprio Eurico também possui algumas características. Encontramos, ainda narrativas em que o narrador explicita que não construirá a sua história a partir de pressupostos verdadeiros, mesmo os conhecendo, de que um exemplo lapidar é "O bispo negro". Lembremos da primeira nota dessa narrativa, em que é afirmado: "A Sé velha de Coimbra é, no todo ou na máxima parte, uma edificação dos fins do século duodécimo; mas aceitamos aqui a tradição que lhe atribui uma remotíssima antiguidade" (Herculano, 1959, p. 818). Também em Garrett encontraremos elementos próximos, especialmente em $\mathrm{O}$ arco de Sant'Ana, com suas poções quase mágicas, vítimas que se transformam em algozes, peripécias que beiram o extraordinário. Em análise, em vários aspectos, próxima da que aqui fizemos, 
Maria Leonor Machado de Sousa aponta que "as primeiras narrativas românticas portuguesas são romances históricos tão sombrios que (...) poderíamos ser levados a classificar de góticos os romances de Herculano (...), de Rebelo da Silva (..) e até de Garrett" (Sousa, 1997, p. 351).

Se tudo isso precisaria, com cuidado e minúcia, ser revisitado e revisto, já pode servir de base para aquilo que, brevemente, gostaria de sugerir. Pareceme que a peculiar trajetória desse estranho realista que foi Eça, em que o realismo quase aparece como um desvio de percurso, só pode ser entendida se pensarmos no papel que correntes não realistas, que poderíamos designar de forma geral como góticas ou de ascendência gótica, possuem na criação da forma romance em Portugal. Se uma biblioteca menor não é só menor, é diferente, pode estar no acervo, não iluminado, talvez romântico, de que surge a prosa eciana, a origem das peculiaridades que a caracterizam, e a distanciam bem mais que a aproximam da dos realistas e naturalistas dos países centrais.

Ora, se aceitarmos a hipótese aqui apresentada, ela pode permitir que atravessemos o Atlântico e olhemos, em outra perspectiva, a obra daquele que é considerado como o nosso principal escritor realista: Machado de Assis. Também nele, mas de forma bastante diversa, encontraremos uma relação entre a obra que escreve e o acervo de leituras de seu público.

Paulo Franchetti, em "O primo Basílio e a batalha do realismo no Brasil", tece algumas considerações que nos podem ser úteis. Após discutir largamente os artigos de Machado de Assis sobre a obra de Eça, inserindo-os no contexto mais geral das outras manifestações sobre o livro do escritor português, e apresentar algumas reflexões acerca de Machado como poeta e crítico da poesia, aponta:

O papel conservador de Machado, no que diz respeito aos rumos da poesia brasileira do final do século XIX, seja como poeta, seja como crítico, está ainda por ser conciliado com a sua apresentação como autor "realista". Um "realista" que se opôs frontalmente, em todos os campos, ao "realismo" (FRANCHETTI, 2007, p. 189).

Para resolver este dilema, de um autor que se opõe ao próprio movimento de que faz parte, o crítico considera que foram realizadas diferentes tentativas de enquadramento, que vão de colocá-lo em uma posição peculiar - como 
ocorre, entre outros, com José Veríssimo e Nelson Werneck Sodré - até a de criar categorias que caberiam apenas para a literatura brasileira, como a tendência mais comum, que foi a de reconstruir "para uso interno, uma oposição realismo/naturalismo, na qual Machado ocuparia o primeiro pólo, que acaba sendo uma espécie de naturalismo mitigado" (FRANCHETTI, 2007, p. 189).

No fim de sua análise considera que:

Parece razoável supor que a crise que Machado viveu em 1878 nasceu também de um impasse propriamente literário, que se poderia resumir nesta pergunta: como abandonar a linha romântica desenhada de Ressurreição (1872) até Iaiá Garcia sem adotar a forma e o estilo do romance realista? A resposta de Machado parece ter sido pôr em prática o que reclamava no final da resenha de O primo: voltou ele mesmo a beber as águas de Garrett e Herculano, além de Camilo (e até águas situadas mais acima na corrente, como as de Sterne e De Maistre), para dar a volta em que ficaria assente a sua genialidade, com Memórias póstumas de Brás Cubas (FRANCHETTTI, 2007, p. 191).

O movimento que o autor do artigo aqui realiza é duplo. Por um lado mostra como a crítica efetua uma espécie de acomodação para poder colocar Machado, e suas idiossincrasias, na história literária, construindo uma aparente versão brasileira desta história, em que realismo e naturalismo se oporiam. Por outro lado, acaba por filiar o autor de Quincas Borba a uma outra tradição, não designada normalmente de realista, em que estariam, entre outros, Herculano, Garrett e Camilo.

Se relacionarmos essas observações de Franchetti sobre Machado com o que apontamos sobre Eça poderíamos concluir que os dois cabem mal nas histórias literárias, pois não podem ser lidos dentro dos modelos que, tendo por base a literatura dos países centrais da Europa, tentam dar conta de autores que escreveram na periferia dos mercados editoriais, e que tinham, por isso, problemas que não ocorriam para um escritor francês ou inglês. $\mathrm{O}$ realismo destes escritores é atípico, pois nenhum deles, do espaço em que produziram, poderiam ser típicos. Da mesma forma como o aparente romantismo de Camilo, e também o problemático romantismo da primeira fase de Machado, parecem pouco ou nada ter daquilo que, na França, por exemplo, pode ser caracterizado como tipicamente romântico. 
Certamente não tenho espaço para desenvolver, com o cuidado necessário, esta hipótese, que venho explorando em vários textos, de forma sempre fragmentária e parcial. Mas não poderia terminar este artigo sem uma visita, mesmo que localizada, a um romance de Machado, mostrando como em sua própria escrita se realiza um embate ente o escritor e o que o seu público dele deseja.

O capítulo XXIV de Esaú e Jacó chama-se "Robespierre e Luís XVI". Os dois inconciliáveis irmãos passaram um dia por "uma loja de vidraceiro", em que haviam para serem vendidos, além de "espelhos de vário tamanho" também "retratos velhos e gravuras baratas, com e sem caixilho". "Pararam alguns instantes, olhando à toa. Logo depois, Pedro viu pendurado um retrato de Luís XVI, entrou e comprou-o (...) Paulo quis ter igual fortuna, adequada às suas opiniões, e descobriu um Robespierre.". Se cada um compra uma imagem, adequada à forma como se vê - afinal estamos numa loja de espelhos - logo em seguida o lojista mostrará um retrato de "Madame de Staël, com o famoso turbante na cabeça”.

O efeito da beleza! Os rapazes esqueceram por um instante as opiniões políticas e ficaram a olhar longamente a figura de Corina. O lojista, apesar dos seus setenta anos, tinha os olhos babados. (...). Como nenhum quisesse comprá-la, talvez por ser só uma, disse-lhes que ainda tinha outra (...) e trouxe uma Diana.

Já voltaremos a este trecho, mas antes vejamos a cena na loja de espelhos termina:

(O lojista) Quis ainda ver se colhia algum dinheiro, vendendo-lhes um retrato de Pedro I, encaixilhado, que pendia da parede; mas, Pedro recusou por não ter dinheiro disponível, e Paulo disse que não daria um vintém pela "cara de traidores". (...) O lojista, tão depressa lhe ouviu a resposta como despiu as formas obsequiosas, vestiu outras indignadas, e bradou que sim, senhor, que o moço tinha razão.

- Tem muita razão. Foi um traidor, mau filho, mau irmão, mau tudo. Fez todo o mal que pôde a este mundo (...). Este moço falou há pouso em rei mártir, - continuou mostrando-lhes um retrato de D. Miguel de Bragança, meio perfil, sobrecasaca, mão ao peito, - este é que foi um verdadeiro mártir 
daquele, que lhe roubou o trono, que não era seu, para dá-lo a quem não pertencia (ASSIS, 1959, p. 906-7).

Segue-se uma negociação para a compra dos retratos de D. Pedro e D. Miguel, mas Pedro, que poderia comprá-las, não as leva, e os dois se retiram.

Paremos aqui um pouco. Temos quatro retratos em uma loja de espelhos. Dois, franceses, são comprados. Outros dois, de portugueses, são deixados de lado, por mais que estejam ligados, de forma evidente, à história mais próxima - não é casual a manifestação passional do lojista - por mais que sejam os retratos de dois irmãos. Pedro e Paulo compram o que desejavam ser - ou o que a sua mãe, que esperava vê-los tornarem-se grandes homens, desejava - e acabam por recusar o retrato mais próximo, o do imperador falhado, que teve de abrir mão de seu império, ou de seu irmão também falhado, que terminou seus dias em amargo exílio.

Se até aqui poderíamos pensar que Machado retrata a forma como o Brasil - é inevitável pensar em Eça - despindo-se de todo o traje português, por mais que lhe caiba melhor, veste-se de trapos vindos de França, o narrador logo nos lembrará que estamos numa loja, em que se vendem retratos mais ou menos novos, melhor ou pior emoldurados.

Após um breve capítulo, temos o seguinte, "A luta dos retratos", que se inicia assim:

Quase que não é preciso dizer o destino dos retratos do rei e o convencional. Cada um dos pequenos pregou o seu à cabeceira da cama. Pouso durou esta situação, porque ambos faziam pirraças às pobres gravuras, que não tinham culpa de nada. Eram orelhas de burro, nomes feios, desenhos de animais, até que um dia Paulo rasgou a de Pedro, e Pedro a de Paulo. Naturalmente, vingaram-se a murro, a mãe ouviu rumor e subiu apressada. Conteve os filhos, mas já os achou arranhados e recolheu-se triste. Nunca mais acabaria aquela maldição de rivalidade? (ASSIS, 1959, p. 908-9)

No fim do capítulo a mãe pensa, que, talvez, a educação efetue o milagre que ela tanto espera:

Foi um recurso hábil separá-los; um ficava no Rio, estudando Medicina, outro ia para São Paulo, estudar Direito. O tempo faria o resto, não contando que 
cada um casava e iria com a mulher para o seu lado. Era a paz perpétua; mais tarde viria a perpétua amizade (ASSIS, 1959, p. 910).

Mas aqui uma nova personagem, habitual nos romances machadianos, surge:

Eis aqui entra uma reflexão da leitora: "mas se duas velhas gravuras os levam a murro e sangue, contentar-se-ão eles com a sua esposa? Não quererão a mesma e única mulher?"

O que a senhora deseja, amiga minha, é chegar já ao capítulo do amor ou dos amores, que é o seu interesse particular nos livros. Daí a habilidade da pergunta, como se dissesse: "Olhe que o senhor ainda nos não mostrou a dama ou damas que têm de ser amadas ou pleiteadas por estes dous jovens inimigos. Já estou cansada de saber que os rapazes não se dão ou se dão mal; é a segunda ou terceira vez que assisto às blandícias da mãe ou aos seus ralhos amigos. Vamos depressa ao amor, às duas, se não é uma só a pessoa...”

Francamente eu não gosto de gente que venha adivinhando e compondo um livro que está sendo escrito com método. A insistência da leitora em falar de uma só mulher chega a ser impertinente. (...), Deixe-se estar quieta, vá de linha em linha; dou-lhe que boceje entre dous capítulos, mas espere o resto, tenha confiança no relator destas aventuras (ASSIS, 1959, p. 910).

A leitora, porém, não precisará bocejar "entre dois capítulos". Já o seguinte se inicia com a frase "Sim, houve uma pessoa, mais moça que eles, um a dous anos, que os agrilhou, à força de costume ou de natureza, se não foi de ambas as cousas" (ASSIS, 1959, p. 911).

Certamente lembramos que o narrador, ao mostrar os dois rapazes olhando para o retrato de Madame de Staël, já havia prefigurado a semelhança no gosto afetivo, em oposição a dessemelhança nas opiniões políticas, que poderia levá-los a amar a mesma mulher. Mas não era qualquer mulher a do retrato, era a da introdutora do romantismo na França. Movimento que nos inundará com livros que moldarão o gosto da leitora que quer logo chegar aos amores. E o narrador, apesar do seu método, tem de ceder e lhe dá, antes que ela boceje, o amor que deseja.

A junção destas cenas pode nos levar a pensar que acabamos por ter aqui ficcionalizada um pouco da questão dos mercados literários que viemos tra- 
tando. O erro que Machado atribuía a Eça - e voltamos à crítica a $\mathrm{O}$ primo Basílio - foi o deste seguir muito à risca o modelo de Zola, no lugar de beber nas águas de Garrett e Herculano. O gosto - presente na cena dos retratos - por Luís XVI, Robespiere e Madame de Staël, gosto que também é o da leitora, não acaba por ocupar o lugar dos retratos - menores, menos brilhantes, mas mais próximos - de D. Pedro e D. Miguel? Não se ficcionaliza aqui a questão apresentada na crítica ao autor português?

Mas, coitado, o narrador escreve romances para um público que já aprendeu a ler no molde francês. E não tem saída senão oferecer, em seguida, o amor que o público pede. Mas que o leitor não se engane. O narrador sabe o que faz. Trapaceia, e muito depois virá a matar a amante que aqui oferece. Poderia haver melhor imagem de um escritor que tenta construir um romance em português brincando habilmente com o gosto do público que tem?

Para concluir este texto que já se faz demasiadamente longo: parece-me, pelo que aqui apontamos, seja tentando tratar de alguns aspectos da obra de Eça, seja nos detendo em um episódio da obra de Machado, que em ambos escritores encontramos uma mesma questão, fruto da específica condição dos espaços em que viveram. Machado e Eça não são inclassificáveis. Apresentam duas respostas possíveis para um problema similar. Tratando com um público ávido de sombras e de amores, constroem, na periferia do mercado editorial oitocentista, um realismo peculiar e instigante.

\section{Referências bibliográficas}

ASSIS, Machado de. Obra Completa I. Rio de Janeiro: Aguilar, 1959.

AUERBACH, Erich. Mimesis. 2a . ed. São Paulo: Perspectiva, 1976.

CARVALHO, Maria Leonor de. A literatura negra ou de terror em Portugal nos séculos XVIII e XIX. Lisboa: Faculdade de Letras da Universidade de Lisboa, 1956.

FRANCHETTI, Paulo. Estudos de literatura brasileira e portuguesa. São Paulo: Ateliê, 2007. MARTÍ-LOPES, Elisa, SANTANA, Mário. Espagna 1843-1900. In: MORETTI, Franco (Org.). Il romanzo - storia e geografia. Torino: Enaudi, 2002, p. 367-377.

MORETTI, Franco. Atlas do romance europeu 1800-1900. São Paulo: Boitempo, 2003.

MULVEY-ROBERTS, Marie (Org.). The handbook to gothic literature. Nova York: New York University Press, 1998. 
QUEIROZ, Eça de. Obra completa vol. I-III. Rio de Janeiro: Nova Aguilar, 1997, 1997a, 2000.

SARAIVA, António José. A Tertúlia Ocidental. Lisboa: Gradiva, 1990.

SCHWARZ, Roberto. Ao vencedor as batatas. São Paulo: Duas Cidades, 1981.

SOUSA, Maria Leonor Machado de. Narrativa de terror. In: BUESCU, Helena Carvalhão. Dicionário do romantismo literário português. Lisboa: Caminho, 1997, p. 350-353.

VARMA, Devendra P. The Gothic Flame being a history of the gothic novel in England: its origins, efflorescence, desintegration and residuary influences. Nova York: The Scarecrow Press, 1987.

VASCONCELOS, Sandra G. T. Dez lições sobre o romance inglês do século XVIII. São Paulo: Boitempo Editorial, 2002.

WATT, Ian. Ascensão do romance. São Paulo: Companhia das Letras, 1990.

Recebido em 03 de maio e aprovado em 15 de junho de 2011. 